\title{
SMARTPHONe APPLiCATIONS - IdEA SOURCING AND APP DEVELOPMENT: IMPLICATIONS FOR FIRMS
}

\author{
John Bredican \\ Division of Industrial Marketing, Royal Institute of Technology (KTH) \\ Debbie Vigar-Ellis \\ School of Management, Information Technology and Governance, University of Kwa-Zulu Natal \\ \& Division of Industrial Marketing, Royal Institute of Technology (KTH) \\ Accepted: January 2014
}

\begin{abstract}
The smartphone has become the uniquely personal computing device choice for consumers. Applications (apps) for smartphones are set to reach revenues of $£ 25$ billion according to Gartner. This presents great opportunities for marketing as apps can provide great benefits for consumers and firms. However it is Information Systems (IS) departments that have traditionally been tasked with the acquisition and/or development of such information technologies within organisations. With such strong implications for marketing, this exploratory research has focused on the sources of app ideas within firms, locations for app development and perceptions of app development success. Results indicate that while most ideas for apps currently come from IS and marketing departments within the organisation, and development of apps is also done mainly within the organisation, these development strategies are not necessarily the most effective. Managerial implications' regarding the role of IS, Marketing and the customer in app development, are discussed
\end{abstract}

Key words: smartphones, apps, IS departments, app usage, app development, customer

JEL: M150

1

\section{Introduction}

By the end of 2011, almost half a billion 'smartphones' had been shipped in the world (MobiThinking, 2012). Added to previously purchased smartphones, this meant that there was a total of around 1.1 billion smartphones in use by the end of 2011. This phenomenon has become known as the 'mobile internet'. Now, over half of all local searches (i.e. by people in their home/city/country locations) are performed on mobile devices. By 2014, the mobile internet will overtake desktop internet usage. More than a third of the over 800 million Facebook subscribers access the social network through a smartphone, and half of all Twitter users use Twitter Mobile (Hepburn, 2011). The smartphone has become the uniquely personal computing device of choice for consumers and a device centric business model the preferred business model for firms in the mobile applications and services market (Hammershoj, Sapuppo \& Tadayoni, 2010).

Smartphones have four defining characteristics: to make and receive telephone calls and text messages, to access the Internet via cellular and/or Wi-Fi networking, to run software applications of the user's choice at the user's discretion, and internal data storage. Individually, these functions can be managed by legacy mobile phones, laptop or tablet computers, but only in smartphones are all four functions integrated into a single device (Bredican, Mills \& Plangger, 2013). Additional common features of Smartphones include camera functionality, multimedia playback and supplementary networking abilities such as Bluetooth, infrared or Near-Field Communication (NFC).

In their wake, smartphones have created the mobile applications market, in which applications (or 'apps') can be made available 
online and downloaded directly onto the device. Gartner predicts the app store revenue for 2013 to reach $\$ 25$ billion dollars (Shevchik, 2013). The smartphone app market is predicted to reach $\$ 58$ billion by 2014. Apps are encapsulated pieces of software that can be used in a variety of ways. Apps can provide benefits to both firms and consumers and will be discussed later.

While research has focused on apps developed for a wide range of contexts such as health (e.g. Bredican et al., 2013; Patel, Nowostawski, Thomson, Wilson \& Medlin, 2013), education (e.g. Woodcock, Middleton, \& Nortcliffe, 2012; Young, 2011), retailing (e.g. Ransom, 2009), tourism and hospitality (e.g. Kim, 2011; Wang, Park, \& Fesenmaier, 2012) and physical location (e.g. Christensen \& Prax 2012; Barba, MacIntyre, \& Mynatt, 2012), very little research has focused the sources of app ideas within firms. This gap in the literature forms the basis of this paper's research questions - where do firms source ideas for apps? Should apps be developed internally or external to the firm and what effects do the sources of app ideas and the development locations have on the firm's satisfaction with the effectiveness and efficiency of apps?

In order to answer these questions, exploratory research was conducted in the form of a survey of a large sample of firms. Given the number of smartphones and mobile devices in use and the prevalence of apps, this potent combination of personal computing hardware and software provides the firm with a uniquely new powerful ubiquitous channel. It is important for marketing to have a strong understanding of how it is perceived in the process of app development in order to be able to better define where and how it can add value to the firm as the role of these new technologies take shape.

The paper proceeds as follows: Following a literature review, it presents the results of a survey conducted on how firms use smartphones apps, how they go about developing proprietary apps for them, and their perceptions of how successful or otherwise this app development is. It concludes by discussing the managerial implications of the findings, the limitations of the study and identifying research avenues for future investigation.

\section{2}

\section{The Rise of the smartphone}

The smartphone is a unique computing device, and its characteristics should be comprehended and incorporated within a firm's information systems. As shown in Table 1, Pitt, Parent, Junglas, Chan, and Spyropoulou (2011:29) contend that smartphones are far more 'unique' devices than Internet-enabled desktop PCs or laptop computers.

The limitations of small screen size and small keyboard make smartphones less fit for tasks like statistical analysis, and are cumbersome for spreadsheet analysis, word processing and presentations. However, PCs do not have localisation or motion detection capabilities, and are awkward to use as calling devices. Some tasks can be performed equally well on both devices, albeit with a different consumer experience. The question of interest is the extent to which firms are exploiting the distinctive capabilities of the smartphone through app development.

\subsection{U-Commerce and smartphone applications}

'U-Commerce' (Watson, Pitt, Berthon, \& Zinkhan, 2002, 2004), provides a theoretical framework for understanding wireless, continuous communication and the exchange of data and the effects of network systems on society and business. 'U-Commerce' (short for Ubiquitous Commerce) can be described as the evolution of E-Commerce (Electronic Commerce); and M-Commerce (mobile commerce); where UCommerce theory includes all forms of value exchange between firm and customer in addition to exchanging money for goods and services and thus expands the boundaries of economic exchange. E-Commerce is based on discrete transactions between (generally) two parties, but U-Commerce is based on the perpetual flow of resources and information through the networked system along all possible connections of consumers, firms and information sources. U-Commerce is defined as "the use of ubiquitous networks to support personalised and uninterrupted communications and transactions between a firm and its various stakeholders to provide a level of value over, above and beyond traditional commerce" (Watson et al., 2002:336). 
Table 1

Differences between a smartphone and an Internet-enabled computer

\begin{tabular}{|c|c|}
\hline Internet-enabled computer & Smartphone \\
\hline Multiple users, family, people in an office & Used typically by only one person \\
\hline $\begin{array}{l}\text { Typically a fixed location. More difficult to carry and use. Lower } \\
\text { battery life (limits portability). }\end{array}$ & $\begin{array}{l}\text { Fully mobile (not place or network dependent). Long- } \\
\text { lasting battery enhances portability. }\end{array}$ \\
\hline $\begin{array}{l}\text { Will only be switched on or accessed when needed. Tethered to } \\
\text { a specific, place-dependent network. }\end{array}$ & $\begin{array}{l}\text { Owners have the smartphone with them for most of their } \\
\text { waking hours, the phone is always on with access to a } \\
\text { ubiquitous network, typically irrespective of place. }\end{array}$ \\
\hline $\begin{array}{l}\text { Owner initiates use. Requires learning multiple programs and } \\
\text { interfaces. Use is more complex, takes longer (e.g., booting the } \\
\text { PC, followed by initiating the program) and less intuitive than the } \\
\text { smartphone. More difficult to configure. }\end{array}$ & $\begin{array}{l}\text { The owner and those who wish to contact them initiate } \\
\text { use. Easy to use (common interfaces, highly-sensitive } \\
\text { touch interface, single Application programming interface } \\
\text { (API)). Easily configurable (home screens, preferences). } \\
\text { Requires little sophistication. }\end{array}$ \\
\hline Multi media device & $\begin{array}{l}\text { Multi media device on the go with advanced, intuitive MM } \\
\text { capabilities. }\end{array}$ \\
\hline $\begin{array}{l}\text { Network provider does not know where that person is } \\
\text { geographically }\end{array}$ & $\begin{array}{l}\text { Multi media device on the go with advanced, intuitive MM } \\
\text { capabilities. }\end{array}$ \\
\hline GPS component, but limited portability. & $\begin{array}{l}\text { Device can pinpoint exact location of owner via GPS } \\
\text { component }\end{array}$ \\
\hline $\begin{array}{l}\text { Some may have accelerometer component built in, but } \\
\text { applications are limited (e.g., bicycling) }\end{array}$ & $\begin{array}{l}\text { Accelerometer and gyroscope, portability means more } \\
\text { potential applications and uses. }\end{array}$ \\
\hline $\begin{array}{l}\text { Applications are available for download. Limited catalogue, } \\
\text { fewer Independent Software Vendors (ISVs), more expensive } \\
\text { (very few are free).applications, typically no 'free', less-functional } \\
\text { versions available. }\end{array}$ & $\begin{array}{l}\text { Many more applications are available for download on the } \\
\text { go and use the unique technical characteristics of device. } \\
\text { More ISVs, lower cost of app (most are free). }\end{array}$ \\
\hline
\end{tabular}

Source: Pitt et al. (2011:29)

U-Commerce includes four major features or defining characteristics: ubiquity, uniqueness, unison and universality (Watson et al., 2002). Ubiquity, is defined as "access to information unconstrained by time and space" (Junglas \& Watson, 2006:578) thus providing users with both time and space convenience (Cliquet, Gonzalez, Huré \& Picot-Coupey, 2013). It represents the ability to be perpetually connected and the integration of human-computer interaction into most devices and processes. 'Always on and always connected' access to information, wherever an individual might be, is a central component of U-Commerce. In a smartphone application, ubiquity refers to the capability of users to access information regardless of where the user happens to be or when they choose to access information.

Uniqueness is "knowing precisely the characteristics and location of a person or entity" (Junglas \& Watson, 2006:579). Customised and individualised information delivered or distributed to or from the individual allows the user to access and generate much more meaningful information than a static, generic interface would allow. Whether by finding information related to a particular geographic area or receiving information based on personal preferences or habits, by virtue of accessing user-specific characteristics the user is able to receive customised, unique data. The goal of Universality is to "overcome the friction of information systems' incompatibilities" (Junglas \& Watson, 2006:580). It relates to multi-functionality. In the name of efficiency and ease, users generally want fewer devices with more functionality. The Smartphone has a high level of integrated functionality such that it can serve as a phone, Personal Digital Assistant (PDA), web browser, music player, camera, GPS, and more. For example, an iPhone customer can search and read reviews for a restaurant (Internet browser) and then click on the displayed phone number (phone) to book a table, then use the map function (GPS) to get there (U-commerce). Compared to other connectable devices that offer multitasking, since Smartphones stay connected through cellular networks and because one of their primary functions is to make and receive telephone calls, the Smartphone is considerably more 'on' than other devices such as PCs and laptops. For example, OpenScape Mobile 
Connect is an enterprise FMC/UC (Fixedmobile convergence / Unified communications) integration solution that seamlessly unifies fixed enterprise VoIP (Voice over Internet Protocol), VoWLAN (Voice over wireless local area network) applications and cellular mobility bringing the full functionality of the worlds most advanced unified communications solution to the iPhone. Besides FMC telephony services, the OpenScape Mobile Client supports instant messaging features to stay efficiently connected with colleagues, independent of the access network (Wi-Fi or Cellular) and the device used (OpenScape MobileConnect V3, 2013).

The fourth characteristic, Unison, is concerned with "information consistency", independent of access point or time (Junglas \& Watson, 2006:580). It concerns data integration across applications and devices (fully synchronised devices such as Smartphone, personal computers, tablet computer at any time) to provide users with consistent and full access to required information, independent of device and location. Compounding the first principle of Ubiquity, consumers require synchronicity between webbased access points and their devices across relevant sources of information such as calendars, documents, list of contacts or emails, rather than uncoordinated, conflicting or out-of-date information from multiple points of access. Unison refers to consistently synchronised access to the user's data in an interactive way (i.e., the ability to pull both data from the server to the device and push data to the server), where information gathering is often coupled with a sense of timeliness and conflicting information is generally seen as inefficiency. For example, OmniFocus for iPhone brings task management to the user's fingertips. The app gives users the ability to keep track of tasks by project, place, person, or date. The users essential information is always at hand, whether it's a shopping list, agenda items to discuss at work, or things to do at home. OmniFocus includes the features to organise tasks, builds task lists based on the users current location, captures voice notes and pictures, and synchronises with a $\mathrm{PC}$ via cloud or WebDAV servers (OmniFocus for iPhone, 2013).

\subsection{Mobile applications, their value and development}

Due to the U-commerce characteristics mobile applications present value to users in key areas such as mobility - the user can conduct business anytime and anywhere, and flexibility - users can engage in other activities such as travelling while conducting business or transactions (Fui-Hoon Nah, Siau \& Sheng, 2005). Additional benefits include ease of use and speed with which information can be accessed as a well-made app can provide a far better user experience than even the best websites. Apps provide convenience, as the device tends to be within arms-length of the user for long periods of time. Apps provide security as they provide safe storage of personal data so that users can save time, and they allow users to purchase items of their choice, from anywhere and at any time. Apps provide entertainment or stress release via games apps, and they assist users' timemanagement (e.g. reminder calendar scheduling). Apps can assist with navigation and trip planning via maps and local information (Wang et al., 2012). A mobile app can also provide offline access to content or perform functions without a network/wireless connection. More than 500,000 applications are available on Apple's App Store for the more than 100 million iPhones in use at present (Apple, 2012). By 2010, Android-based phones had more than 20,000 applications at their choosing, Windows Mobile users approximately 1,000 and Blackberry users around 5,000 applications (Hoogsteder, 2010).

According to Teng and Helps (2010:471) "a recent IDC (www.idc.org) survey suggests that 70 per cent of organisations are currently deploying at least one mobile application, with more than a third of these companies deploying multiple mobile applications". Mobile apps have various benefits for firms; they can help build relationships, reinforce the brand and build loyalty. Business visibility and accessibility can be increased as well as increasing sell-through and connections with on-the-move consumers. Communication is not trapped in spam folders and apps have the potential to increase repeat business. Apps can enhance social networking strategy, provide 
faster access than a mobile website and can function off-line (Features Learn More, 2013). Apps can also transform the delivery of information about customers to firms (White, 2010). Business enterprises are embracing mobility as a new strategic opportunity to unleash new ways of doing business (Perelson $\&$ Botha, 2004). In some instances activities such as scheduling, billing, information-seeking, records management and communications which were once the domain of the business can be shifted to the customer or consumer, thus lowering company costs while providing greater flexibility and convenience for the customer or consumer. Furthermore, research shows that customers are actually more satisfied with such owned and self-managed experiences, as they feel more ownership of and control over their interactions with firms (e.g. Bendapudi \& Leone, 2003). 'Always on and always connected' means that firms can expect partners and customers to react quickly to what may be happening at any point within any business process. Thus apps can be beneficial to both firms and individuals and for firms, can improve internal functioning as well as external activities i.e. aimed at improving customer interaction and satisfaction.

These applications can be developed by individuals, existing- and start-up software firms, and by firms that view applications as a unique way to reach out externally to business partners and customers, to reach out to consumers, and internally to target a company's workforce and internal business processes. Some applications bridge both the internal and external audiences - for example, real time mobile business intelligence extends to consumers in the act of 'consuming' services, but then feeds back that information to internal business teams for analysis and action. Kangas and Kinnunen (2005), state that opportunities for app development are increasing. The Internet abounds with advise on developing mobile apps and the tightening economic climate encourages entrepreneurs to develop mobile apps (Kirk \& Rouge, 2011). Thus there are many firms offering app development services. Bernoff and Schadler (2010) encourage firms to empower employees to provide the solutions to customer problems using the technologies used by these customers. There are many sources of ideas for apps: observing the competition, suggestions by customers, and departments within the firm itself, including the IS and marketing functions. Employees in departments such as marketing who are likely to have greater interaction with customers should be in an equally favorable position to identify ideas for app development as IS departments.

\section{3}

\section{A study of smartphone app development and perceptions of effectiveness}

\subsection{Methodology}

Using the client database of a large international IS consulting firm, by means of an email questionnaire, 970 IS executives in various parts of the world were questioned in order to assess the extent of smartphone app use, the sources of app ideas, the location of app development and managers' perceptions of the effectiveness of these processes. By contractual obligation, all clients are required to respond to surveys conducted by the consultancy, which effectively results in a 100 per cent response rate. As a filter question, respondents were required to indicate whether their firm was utilising smartphone apps in any way or not. Firms using smartphone apps in some way amounted to 239 firms, therefore only these firms were included in the analysis discussed in this paper, resulting in an effective response rate of 24.6 per cent. These executives came from the full spectrum of company and IS department sizes, from the very large to the very small, with varying degrees of financial resources, and from countries including the USA, Canada, Australia, New Zealand, United Kingdom, Ireland, France, Germany, Sweden, Spain, and South Africa. The survey questionnaire utilised various categorical responses to group respondents as well as Likert-type scales to assess various aspects of perceived app performance.

\subsection{Findings}

The first question required respondents to indicate whether apps that they used were primarily for internal or external use. Among 
the 239 firms that are using smartphone apps, as can be seen in Table 2, all firms to some extent use them both internally and externally.
There does however, seem to be some potential for expanded use in the future.

Table 2

Extent of app use for external and internal use

\begin{tabular}{|l|c|c|}
\hline \multicolumn{1}{|c|}{ Use of smartphone apps } & For external use & For internal use \\
\hline Not at all & $1 \%$ & $13.4 \%$ \\
\hline To a very small extent & $59.8 \%$ & $33.1 \%$ \\
\hline Somewhat & $21.3 \%$ & $35.6 \%$ \\
\hline To a large extent & $11.3 \%$ & $14.6 \%$ \\
\hline To a very great extent & $6.6 \%$ & $3.3 \%$ \\
\hline Total & $100 \%$ & $100 \%$ \\
\hline
\end{tabular}

The respondents were then asked to indicate the main purpose for which the apps were developed for external use. The possibilities were centered on the simple provision of information (for example, an airline providing a flight schedule), or the facilitation of realtime service (for example, a passenger booking a ticket on an airline). The results for this question are presented in Table 3. It can be seen that the majority of apps are developed to provide customers with a mix of information and real-time service (40.5 per cent of apps), or simply to provide information (25.9 per cent of apps).

Table 3

Main purpose of apps developed for customers

\begin{tabular}{|l|c|}
\hline \multicolumn{1}{|c|}{ Main purpose of smartphone app(s) } & Percentage of respondents \\
\hline Mostly to provide information to customers & $25.9 \%$ \\
\hline Mostly to provide real-time service to customers & $10.9 \%$ \\
\hline Only to provide information to customers & $16.7 \%$ \\
\hline Only to provide real-time service to customers & $5.0 \%$ \\
\hline To provide a mix of information and real-time service to customers & $40.5 \%$ \\
\hline We do not use apps to interact with customers. & $1.0 \%$ \\
\hline TOTAL & $100 \%$ \\
\hline
\end{tabular}

The source of the idea for the app was also of interest. As can be seen from Table 4, the ideas for apps came mainly from the IT department (in 41 per cent of cases) followed by the Marketing department (20.1 per cent). Customers also seem to be a fairly common source of ideas for apps (in around 18 per cent of cases), while in some firms ideas for apps came from other departments than IS or Marketing. Some firms were obviously monitoring the business environment closely, observing what other firms or competitors were doing, and implementing similar ideas.

Table 4

Main source of ideas for smartphone apps

\begin{tabular}{|l|c|}
\hline \multicolumn{1}{|c|}{ Main source of ideas for a smartphone app } & Percentage of respondents \\
\hline Observing other firms, including our competitors & $7.5 \%$ \\
\hline Other departments in the firm & $13.4 \%$ \\
\hline Our customers & $18.0 \%$ \\
\hline Our information systems department & $41.0 \%$ \\
\hline Our marketing department & $20.1 \%$ \\
\hline TOTAL & 100.0 \\
\hline
\end{tabular}


Firms developing apps face the choice of either doing this for themselves, relying on outside suppliers, or some combination of these alternatives. Table 5 shows that only a few respondents relied on outside suppliers to any great extent, so that the majority of smartphone app development is done internally, or with some degree of outside help. As has previously been noted, this is an interesting shift in the nature of the IS department's work: Until 2008, (when the Apple App Store was established) this task simply didn't exist in the IS department or anywhere else (Pitt, Berthon \& Plangger, 2012).

Table 5

Location of app development

\begin{tabular}{|l|c|}
\hline \multicolumn{1}{|c|}{ Location of app development } & Percentage of respondents \\
\hline Completely within the firm & $36.4 \%$ \\
\hline Within the firm but with some outside help & $36.0 \%$ \\
\hline A $50-50$ mix of the firm and outside help & $10.0 \%$ \\
\hline Mostly with outside help & $13.4 \%$ \\
\hline Completely by a supplier outside of the firm & $4.2 \%$ \\
\hline TOTAL & $100 \%$ \\
\hline
\end{tabular}

The next objective was to determine the impact of the idea source on four outcome variables: satisfaction with the app development process, perception of app effectiveness, satisfaction with cost effectiveness of the app, and the perceived innovativeness of the app itself. A series of simple one-way analysis of variance (ANOVA) procedures was run in order to explore these relationships. From Table 6 it is evident that idea source does significantly affect all outcome variables.

Table 6

Analysis of variance: idea source

\begin{tabular}{|l|c|c|c|c|c|c|c|c|}
\hline \multicolumn{1}{|c|}{ Variable } & $\begin{array}{c}\text { SS } \\
\text { effect }\end{array}$ & $\begin{array}{c}\text { df } \\
\text { effect }\end{array}$ & $\begin{array}{c}\text { MS } \\
\text { effect }\end{array}$ & $\begin{array}{c}\text { SS } \\
\text { error }\end{array}$ & df error & MS error & F & Prob. \\
\hline App. devt. satisfaction & 22.410 & 4 & 5.603 & 163.104 & 234 & 0.697 & 8.038 & $<.001^{*}$ \\
\hline App. effectiveness & 42.374 & 4 & 10.594 & 162.496 & 234 & 0.694 & 15.255 & $<.001^{*}$ \\
\hline Sat. with app cost effectiveness & 16.168 & 4 & 4.042 & 97.790 & 234 & 0.418 & 9.672 & $<.001^{*}$ \\
\hline App innovativeness & 38.520 & 4 & 9.630 & 84.409 & 234 & 0.361 & 26.696 & $<.001^{*}$ \\
\hline
\end{tabular}

* Significant at a 1 per cent level,

To further investigate these differences, the Tukey-Kramer procedure was applied to determine which means were significantly different (Levine, 2004). Means-diamond plots visually compare the mean and standard error for each sample group. The line across each diamond represents the group mean, the apex of the diamond represents the 95 percent confidence interval for each group, and the width is the group sample size (Gigawiz, 2012). The analysis is also made visually simple by assigning letters (e.g. A, B, C) to each predictor variable, so that variables with the same letter (e.g. A) are not significantly different from each other, and those with different letters (e.g. A versus B or C) are significantly different to each other (SAS, 2012).
Thus looking firstly at the IS managers' perceived satisfaction with the app development, this outcome variable was measured on a single item 5-point scale ranging from $1=$ very dissatisfied through $5=$ very satisfied. Figure 1 presents the results of the Tukey-Kramer post hoc test and shows that the mean satisfaction with the app development was significantly higher when the source of the app was other departments in the firm (A). There were no significant differences between the means of any of the other sources of app ideas (B).

For the second output variable: the app's perceived effectiveness, the variable was measured on a single item 5-point scale ranging from $1=$ very ineffective through $5=$ very effective. Figure 2 presents the effects of the idea source 
on perceptions of app effectiveness and indicates that the mean perception of app effectiveness was significantly higher when the source of the app was other departments in the firm (A). Perceptions of app effectiveness were significantly lower for benchmarking on other firms than for any other source (C).

Figure 1

Effects of idea source on app development satisfaction

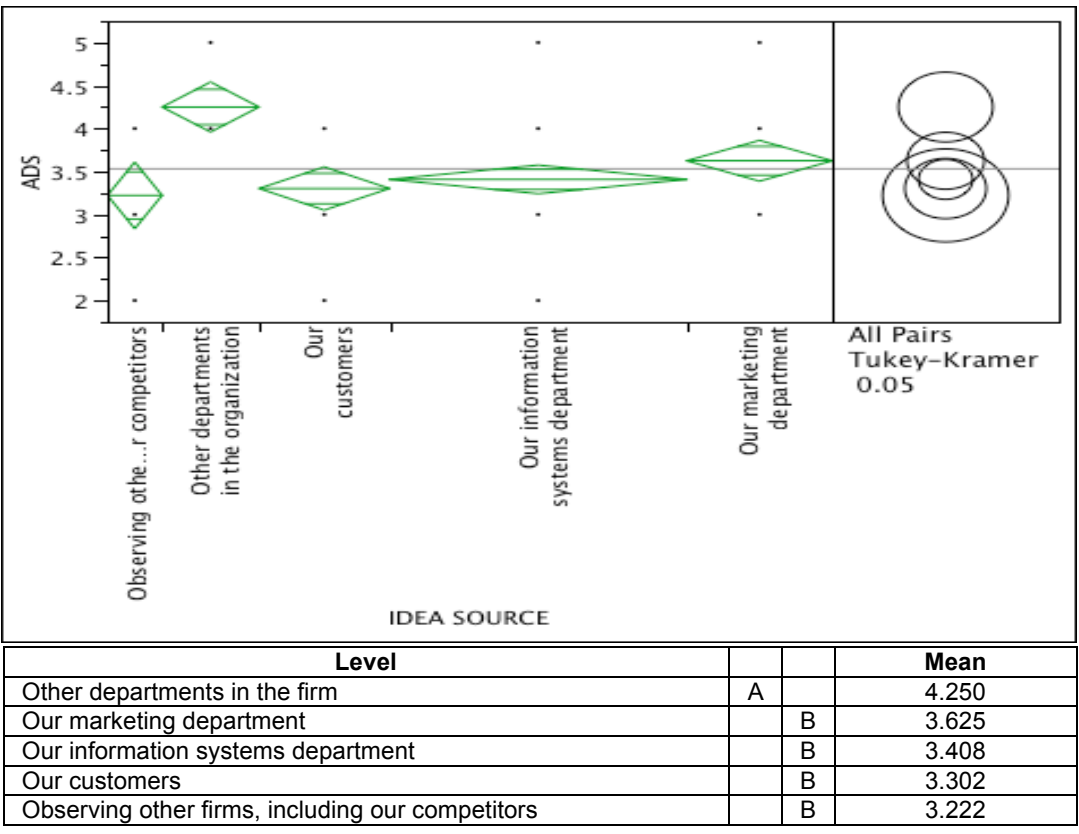

Figure 2

Effects of idea source on perceptions of app effectiveness

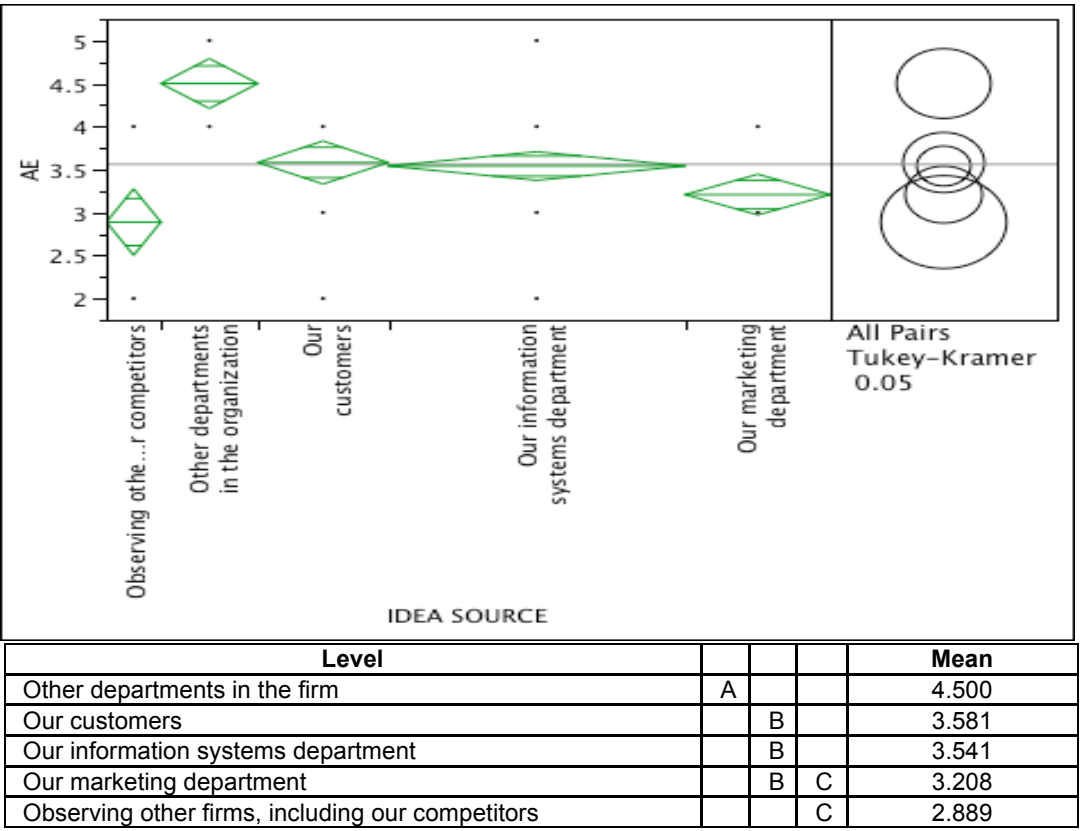


The third outcome variable was perceived satisfaction with the app's cost effectiveness (the value of the benefits is more than the costs associated with the design, build, adoption and adaptation of the mobile application i.e. value for money, given the early adoption of this technology the benchmark indicator is return on investment). Satisfaction with the app's cost effectiveness was measured on a single item 5point scale ranging from $1=$ very dissatisfied with the app's cost effectiveness through $5=$ very satisfied with the app's cost effectiveness. Figure 3 presents the effects of the idea source on perceptions of the app's cost effectiveness.
As may be expected, there are significantly higher levels of satisfaction with app cost effectiveness when the source of app ideas are internal sources particularly the $I S$, and other departments (A), rather than external sources (customers (B) and observing competitors (C)). However it is interesting that satisfaction with cost effectiveness of the app was not significantly higher when the source of the app idea was the marketing department rather than the customer, although satisfaction was higher than if the source was other companies or competitors.

\section{Figure 3}

Effects of idea source on perceptions of app cost effectiveness

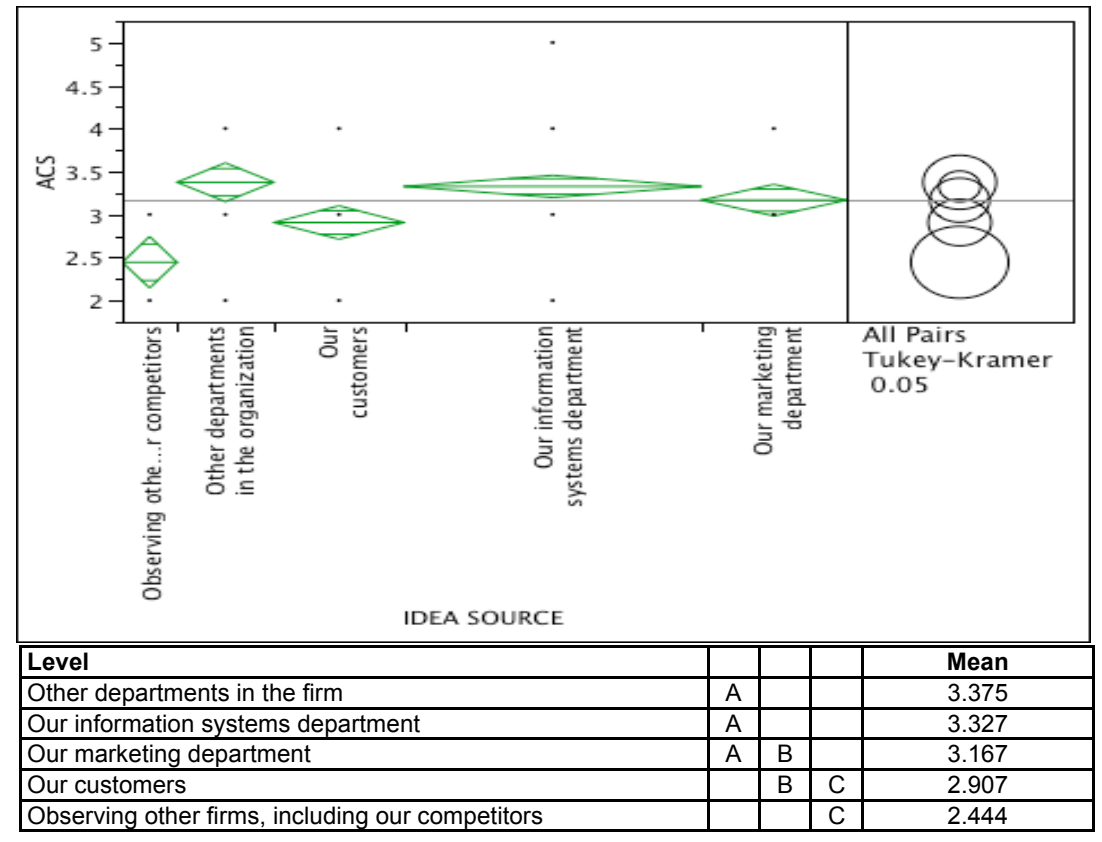

The last effect of idea source that was tested was on the perceived app innovativeness. The app's perceived innovativeness was measured on a single item 5-point scale ranging from $1=$ not very innovative at all through $5=$ very innovative (not innovative indicates an off-theshelf app, while a very innovative app would indicate a new ground-breaking, highly productive app). Figure 4 presents the effects of the idea source on perceptions of the app's innovativeness and indicates that there are significantly higher levels of perceived app innovativeness when the source of app ideas are other departments (A), the IS department or customers. App ideas from other companies (B) and the marketing department were perceived to be significantly less innovative. 
Figure 4

Effects of idea source on perceptions of app effectiveness

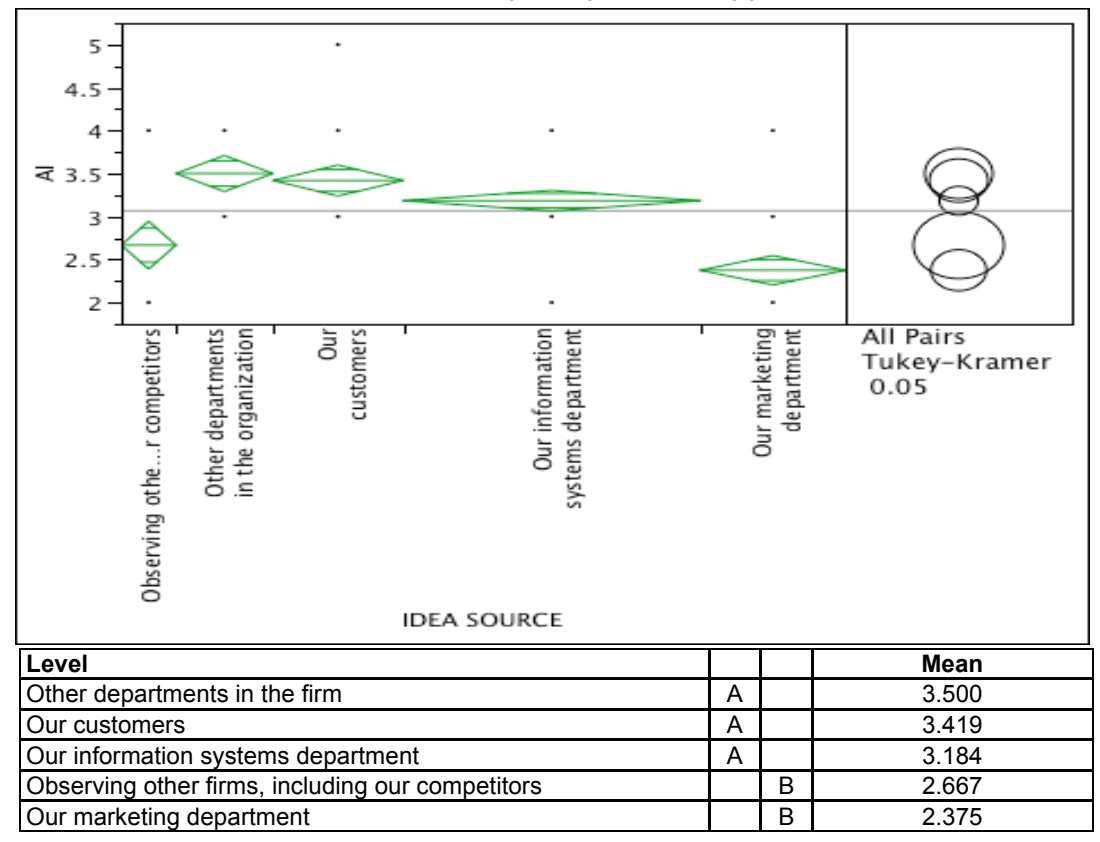

The final set of analyses sought to determine the effect that development location had on satisfaction with the app development process, perception of app effectiveness, satisfaction with the cost effectiveness of the app, and the innovativeness of the app itself. Firms can develop apps themselves, rely on outside suppliers, or use some combination of these alternatives. The same analyses were conducted as above. From Table 7 it is evident that the location of app development does significantly affect all outcome variables.

Table 7

Analysis of variance: Development location

\begin{tabular}{|l|c|c|c|c|c|c|c|c|c|}
\multicolumn{1}{|c|}{ Variable } & $\begin{array}{c}\text { SS } \\
\text { effect }\end{array}$ & $\begin{array}{c}\text { df } \\
\text { effect }\end{array}$ & $\begin{array}{c}\text { MS } \\
\text { effect }\end{array}$ & $\begin{array}{c}\text { SS } \\
\text { error }\end{array}$ & $\begin{array}{c}\text { df } \\
\text { error }\end{array}$ & $\begin{array}{c}\text { MS } \\
\text { error }\end{array}$ & F & Prob. \\
\hline App. devt. satisfaction & 16.769 & 4 & 4.192 & 168.746 & 234 & 0.721 & 5.814 & $<.001^{*}$ \\
\hline App. effectiveness & 37.644 & 4 & 9.411 & 167.226 & 234 & 0.715 & 13.169 & $<.001^{*}$ \\
\hline Sat. with app cost effectiveness & 13.736 & 4 & 3.434 & 100.223 & 234 & 0.428 & 8.018 & $<.001^{*}$ \\
\hline App innovativeness & 20.085 & 4 & 5.021 & 102.844 & 234 & 0.440 & 11.425 & $<.001^{*}$ \\
\hline
\end{tabular}

* Significant at a 1 per cent level,

Again to investigate these differences further, the Tukey-Kramer procedure was applied to determine which means were significantly different and means-diamonds plots provide a visual basis for comparison. Figure 5 presents the results looking at the effect that the location of the app development has, essentially externally or internally, on the satisfaction with the app development. The results indicate that apps developed completely by an outside supplier (A) have significantly higher satisfaction levels than all other development locations except the 50-50 internal-external mix. Satisfaction with the development of apps was significantly lower for apps developed entirely within the firm (C) and those developed mostly by an outside supplier (but with some inside involvement). It would therefore seem as though an 'all or nothing'- or a 50-50 cooperation approach works best: Marginal involvement from either side, or a solely internal approach are perceived as less effective. 
Figure 5

Effects of development location on app development satisfaction

\begin{tabular}{|l|l|l|l|}
\hline & & \\
\hline \\
L
\end{tabular}

In Figure 6 it can be seen that there are significantly higher levels of perceived app effectiveness for apps developed either by means of a 50-50 mix of the firm and outside help, within the firm but with some outside help, or completely by a supplier outside of the firm (A) than if the app is developed within the firm entirely, or within the organisation with

Figure 6

Effects of development location on perceived app effectiveness

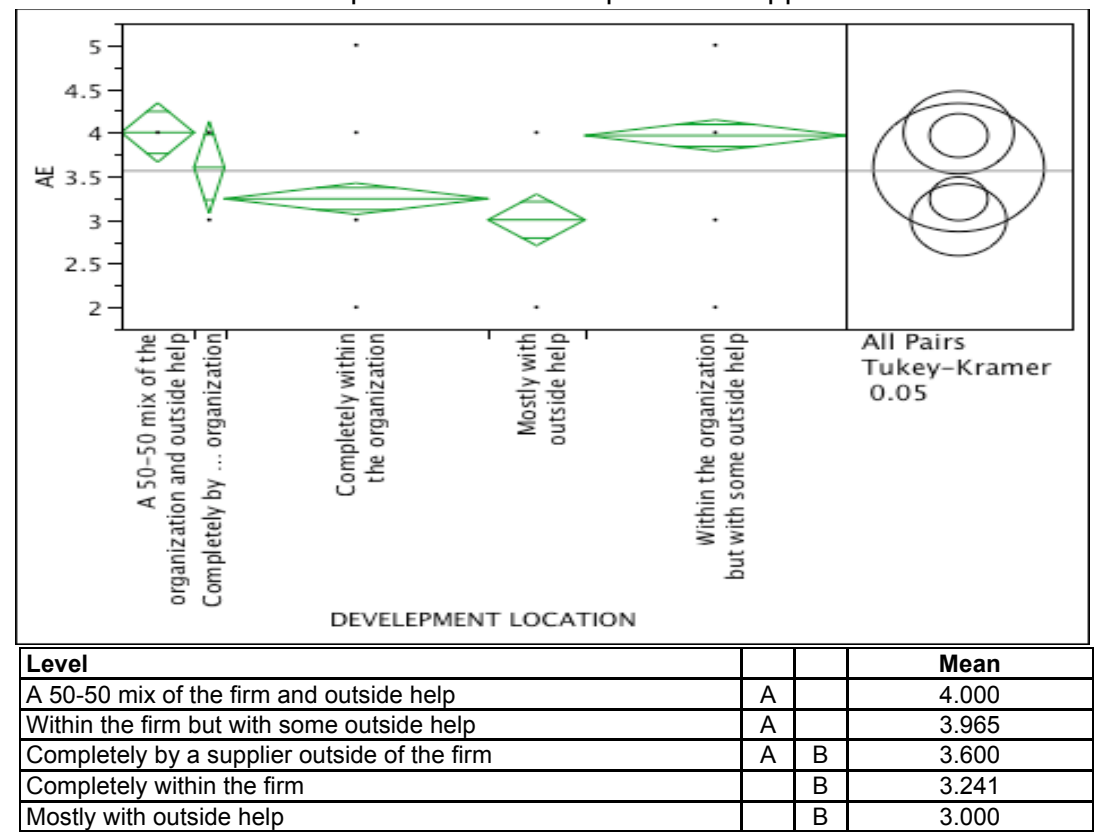


some outside help. Perceived app effectiveness again was significantly lower for apps developed entirely with the firm and those developed mostly with outside help (B).

Figure 7 presents the results looking at the effect that the location of the app development has on the satisfaction with the app cost effectiveness. Figure 7 indicates that apps developed within the firm but with some outside supplier help (A) have significantly higher satisfaction with the app cost effectiveness levels. Apps developed completely by an outside supplier (C) were however perceived to be significantly less cost effective.

Figure 7

Effects of development location on satisfaction with the app cost effectiveness.

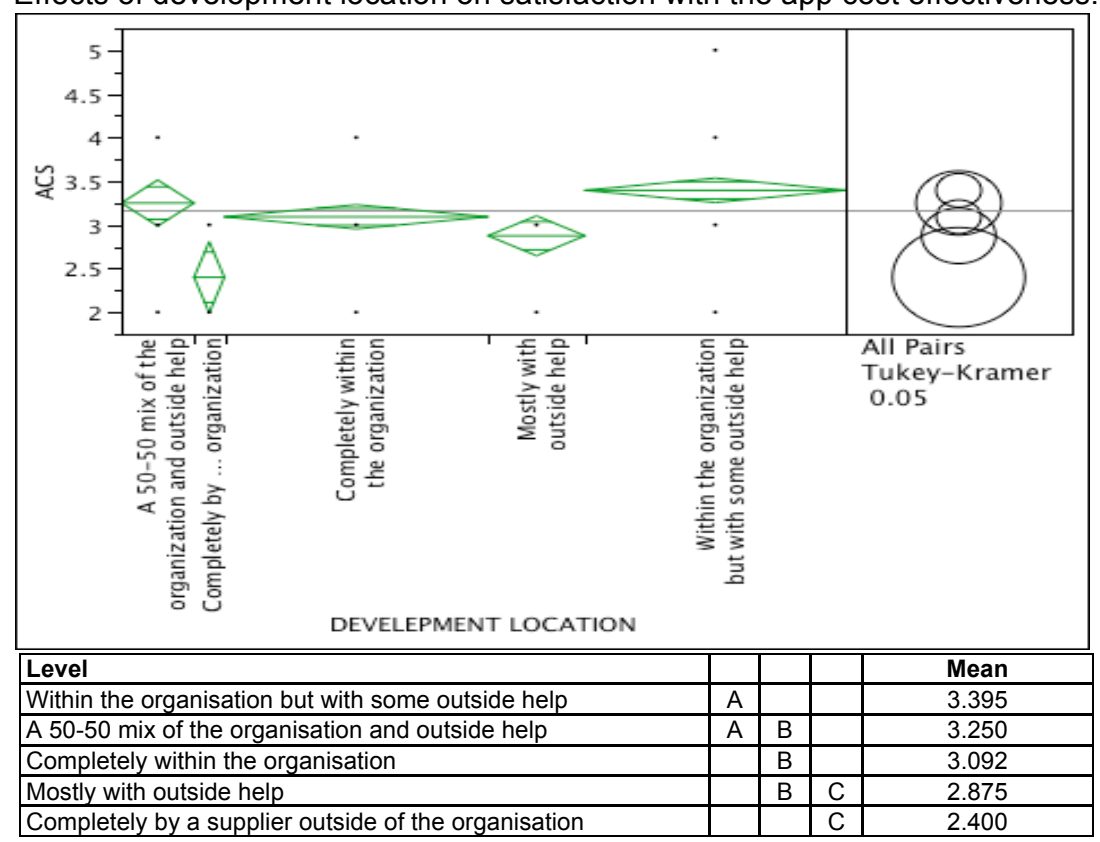

Finally, the last effect of development location that was tested was on the perceived app innovativeness. Figure 8 reveals that there are significantly higher levels of perceived app innovativeness when the apps are developed entirely by an outside supplier or within the firm but with some outside help (A).

It seems that with regard to the location of app development the IS managers in this survey perceived different locations to be useful for achieving different effects:

1) Outside suppliers are perceived to be able to offer innovative apps and provide a high level of app development satisfaction.

2) A 50-50 mix of internal and external suppliers of apps can achieve similar levels of app development satisfaction but with the added benefits of perceived app effectiveness and cost effectiveness.

3) As expected, app development within the firm would be the most cost effective.

\section{4}

Managerial implications, limitations and future research

Smartphone use has risen dramatically, and will continue to rise. This increase in smartphone use will see a similar growth in app development for firms. The results of this survey of IS managers indicates that smartphone apps are being developed for both internal and external uses. Although use might be moderate at present, it is likely that this will increase in the future as device prices decrease, network availability improves, consumer and employee mobility increases and individuals become reliant on the apps on their devices for daily functioning. Smartphones today are far more integrated into people's lives than any 
other technology (Gilbert \& Kendall, 2003:8). Firms able to capitalise on these opportunities should enjoy significant advantages.

Figure 8

Effects of development location on perceived app innovativeness

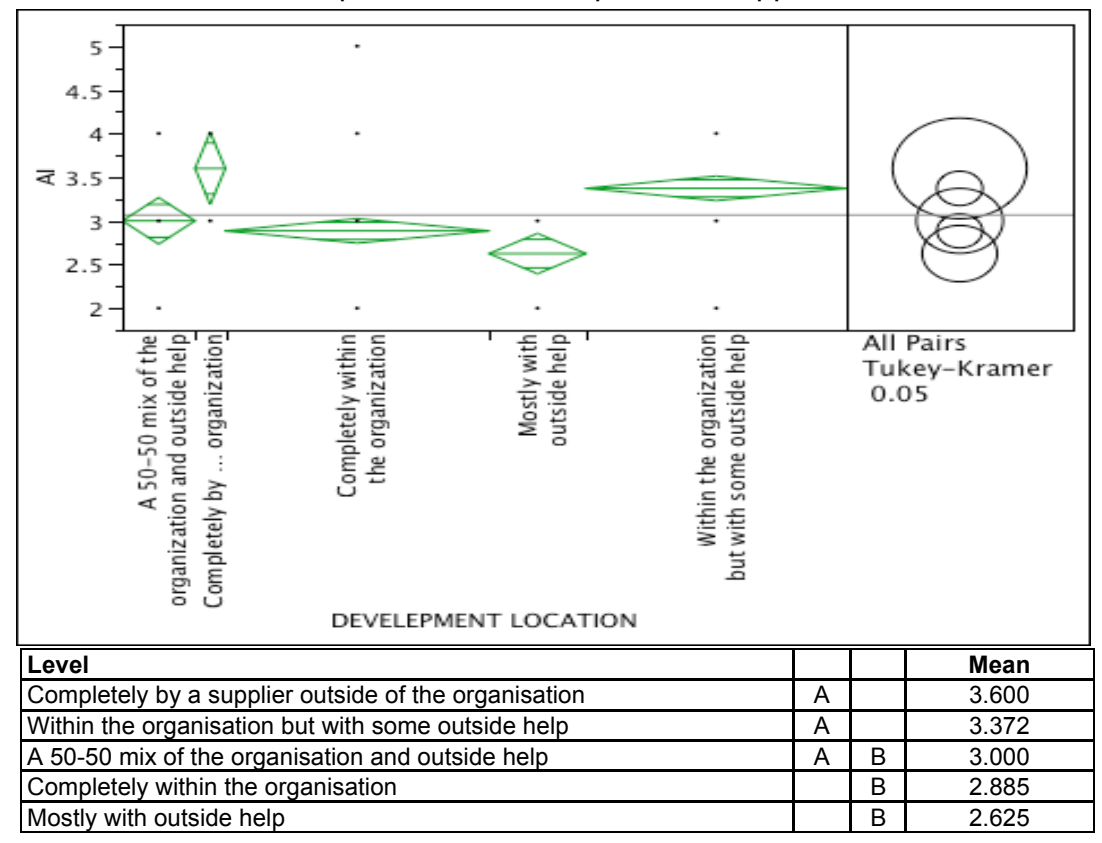

For firms using IS to compete effectively, the rise of the smartphone has important implications. First, these devices raise issues that hardly existed just a few years ago. Apps didn't exist but their development and use is likely to become a far greater priority for firms in the future. Second, as more and more jobs in firms evolve, at least partially, the use of devices and the role of the firm's IS department is likely to change. Today the devices used by employees are less likely to be owned by the firm and thus directly under the control of its IS department, but are more likely to be bought and owned by individual employees. Pitt et al. (2012) argue that the distinction between what a firm owns and does, and what the individual owns and does, is no longer distinct and that the smartphone device and apps are part of what DesAutels (2011:185) terms the "user-generated information system" (UGIS) - a system developed by the user without IS skills or knowledge. Such systems would not be under the direct control of the IS departments within those firms. The results of this study indicate that IS managers see other departments, the users of apps and the developers of UGISs as the most effective and satisfying source of app ideas. The days of the IS department being the 'sole providers' of IS ideas and solutions seem to be diminishing.

Third, user-generated information systems do not only influence employees, the use of smartphones and apps also influence the role of the customer. Customers will use their own devices to perform many tasks formerly carried out by the firm and its employees. As confirmed by this study, customers thus represent a good source, particularly of innovative app ideas. Actively seeking customer input and then developing apps to satisfy these needs could provide firms with the edge to attract and retain customers. As a key link between customers and firms, marketing departments may need to address the perception at least amongst IS managers, of being a relatively poor source of app ideas.

This study is subject to a number of limitations. First, while the findings of the study might be generalisable to some extent, 
the study does not provide any depth richness or context. Put simply, the study sheds light on what is happening, but tells us very little about why it is happening. For example, while we know from the study that other departments or functions in a firm, other than marketing or IS tend to be useful sources of app development, this study did not attempt to discover what those other functions were. This could only be achieved by an in-depth study. Unstructured interviews with IS executives could allow one to identify this. It may indeed differ from firm to firm.

Since mobile apps first appeared along with the Smartphone in 2007, mobile app purchases on Apples App Store have just exceeded 50 billion (Apple, 2013). The biggest app category on the Apple app store is games with business applications accounting for only 6.4 per cent (Research2guidance, 2013). Despite the IDC report by Teng and Helps (2010:471) stating that " 70 per cent of organisations are currently deploying apps" it is noted that of the 970 firms polled in this research, only 239 firms were using smartphone apps in any way, an effective response rate of 24.6 per cent. In the consumer world mobile apps have become ubiquitous, but it seems, at least from this study, that the majority of firms are in the early adoption phase. Understanding what the obstacles to enterprise mobile adoption, implementation and success are, is an area for future research.

The study did not utilise a random sample in the true sense. Instead, the client base of a large IT consulting firm was used as the sample frame. Future studies may compare app development across developed and developing countries.

Fourth, the study also suffers from the limitations of all email surveys in that the researcher can never be certain of who is actually completing the questionnaire. While the responses were purportedly made by IS executives, it is impossible to be certain that someone else, such as a personal assistant, completed the survey instead.

The study also highlights opportunities for research into this important domain. First, as already noted, depth interviews with senior executives, and case studies of firms implementing particularly successful or unsuccessful apps will provide the richness, context and depth that this survey was unable to offer. Second, while this study covered a number of different countries, there was no attempt to do any cross-cultural or across-country comparisons. It would be worthwhile to explore whether development practices and perceptions of effectiveness differ across countries, and also to include a broader spectrum of countries in the study. Furthermore, future research could also study differences between firms based on demographic indicators such as type of industry, size of firm, and age of firm. Finally, if this study were to be repeated over time, the researcher could gain insight into whether longitudinal trends would emerge. For example, while many firms seem to be relying on outside suppliers for app development at present, as they were able to build the required skills internally and empower employees with such skills, perceptions of both internal and external app development effectiveness might change.

\section{5}

\section{Conclusion}

Amongst this sample of IS executives app development has been moderate but with both internal and external uses. This survey indicates that the majority of external apps are developed to provide customers with a mix of information and real-time services. Sources of ideas for these apps come mainly from IS departments and to a lesser extent, marketing departments. It is interesting to note however, that when one considers measures of satisfaction with app development and app cost effectiveness, and perceptions of app effectiveness and innovativeness, other departments were perceived to be significantly better sources of ideas for apps. IS departments were perceived to be good sources of app ideas only when it came to satisfaction with cost effectiveness and app innovativeness. Marketing departments seem not to be good sources of app ideas for any of the measures chosen. Ranked third as the most commonly perceived source of app ideas are customers, and significantly they were found to be a good ideas source only when it came to providing apps perceived to be innovative. 
Apps were developed predominantly inhouse, or with some external supplier help. Only a small number of the firms in the sample actually used external suppliers completely or to a large extent and yet outside suppliers were perceived to provide significantly higher levels of app development satisfaction and app innovativeness. Even a 50-50 split between internal and external developers yielded significantly higher results for app development satisfaction, perceived app effectiveness and satisfaction with app cost effectiveness. Internal developers were significantly better for app cost effectiveness satisfaction, which is to be expected and internal development with some help from outside suppliers was significant for app innovativeness. Thus it seems at least in a 50-50 split that the use of outside suppliers could considerably increase effectiveness measures of satisfaction with app development and cost effectiveness, and perceived app effectiveness and innovation.

\section{Acknowledgements}

The authors wish to acknowledge the contributions of the reviews in improving the quality of this paper. Their suggestions were extremely helpful and gratefully appreciated.

\section{References}

APPLE. 2012. Apple iPhone. Available at: http://www.apple.com/iphone/built-in-apps/app-store.html [accessed 2012-09-17].

APPLE. 2013. Apple. Available at: http://www.apple.com [accessed 2012-05-16].

BARBA, E., MACINTYRE, B. \& MYNATT, E.D. 2012. Here we are! Where are we? Locating mixed reality in the age of the smartphone. Proceedings of the IEEE, 100(4).

BENDAPUDI, N. \& LEONE, R. 2003. Psychological implications of customer participation in co-production. Journal of Marketing, 67(1):14-28.

BERNOFF, J. \& SCHADLER, T. 2010. Empowered: Unleash your employees, energize your customers, and transform your business. Harvard Business School Press.

BREDICAN, J., MILLS, A.J. \& PLANGGER, K. 2013. iMedical: Integrating smartphones into medical practice design. Journal of Medical Marketing: Device, Diagnostic and Pharmaceutical Marketing, 13(1): 5-13.

CHRISTENSEN, C. \& PRAX, P. 2012. Assemblage, adaptation and apps: Smartphones and mobile gaming. Journal of Medical \& Cultural Studies, 26(5):731-739.

CLIQUET, G., GONZALEZ, C., HURÉ, E. \& PICOT-COUPEY, K. 2013. From mobile phone to smartphone: what's new about m-shopping? Paper presented at the Ideas In Marketing: Finding the New and Polishing the Old, Proceedings of the Annual Conference of the Academy of Marketing Science, May 2013, Monterey, CA USA.

DESAUTELS, P. 2011. UGIS: Understanding the nature of user-generated information systems. Business Horizons, 54(3):185-192.

FEATURES LEARN MORE. 2013. Available at: www.mobileapploader.com: http://mobileapploader.com/ myapp/FeaturesLearnMore.aspx [accessed 2012-04-25].

FUI-HOON NAH, F., SIAU, K. \& SHENG, H. 2005. The value of mobile applications: a utility company study. Communications of the ACM, 48(2):85-90.

GIGAWIZ. 2012. One-way between-subjects ANOVA: Diamond mean comparison plot. Available at: http://www.gigawiz.com/anova1.html [accessed 2012-09-17].

GILBERT, A.L. \& KENDALL, J.D. 2003. A marketing model for mobile wireless services. Proceedings of the 36th Annual Hawaii International Conference on System Sciences, Jan, 6-9. doi: 10.1109/HICSS.2003. 1174216.

HAMMERSHOJ, A., SAPUPPO, A. \& TADAYONI, R. 2010. Challenges for mobile application development. Paper presented at the Intelligence in Next Generation Networks (ICIN):2010 14th International Conference, October 2010, p 1-8, IEEE. 
HEPBURN, A. 2011. Infographic: Mobile statistics, stats \& facts 2011. Digitalbuzz. 4 November, 2013, from http://www.digitalbuzzblog.com/2011-mobile-statistics-stats-facts-marketing-infographic/. [Accessed 201211-04].

HOOGSTEDER, V. 2010. Our presentation from Mobile World Congress 2010 - Mobile application stores state of play. Available at: http://blog.distimo.com/2010_02_our-presentation-from-mobile-world-congres2010-mobile-application-stores-state-of-play/ [accessed 2012-09-17].

JUNGLAS, I. \& WATSON, R.T. 2006. The u-constructs: four information drives. Communications of the Association for Information systems, 17(1):26.

KANGAS, E. \& KINNUNEN, T. 2005. Applying user-centered design to mobile application development. Communications of the ACM, 48(7):55-59.

KIM, D. 2011. Student's use of hotel mobile apps: Their effect on brand loyalty. Available at: http://scholarworks.umass.edu/gradconf_hospitality/2011/Poster/38/ [accessed 2012-11-04].

KIRK, G.A. \& ROUGE, B. 2011. There's an app for that, but is there a market for that app? An exploration of the app market as an avenue for entrenpreneurship. Issues in Information Systems, 12, 313-117.

LEVINE, D.M. 2004. Statistics for managers using Microsoft Excel ( $4^{\text {th }}$ ed.) Upper Saddle River, New Jersey: Prentice Hall.

MOBITHINKING. 2012. Global mobile statistics 2012 Part A: Mobile subscribers; handset market share; mobile operators. Available at: http://mobithinking.com/mobile-marketing-tools/latest-mobile-stats/ a\#smartphone-shipments [accessed 2012-09-17].

OMNIFOCUS FOR IPHONE. 2013. Available at: https://itunes.apple.com/gb/app/omnifocus-for-iphone/ id284885288? $\mathrm{mt}=8$ [accessed 2012-04-20].

OPENSCAPE MOBILECONNECT V3. 2013. Available at: https://itunes.apple.com/gb/app/openscapemobileconnect-v3/id375082716? $\mathrm{mt}=8$ [accessed 2012-04-13].

PATEL, V., NOWOSTAWSKI, M., THOMSON, G., WILSON, N. \& MEDLIN, H. 2013. Developing a smartphone 'app' for public health research: the example of measuring observed smoking in vehicles. Journal of epidemiology and community health, 67(5):446-452

PERELSON, S. \& BOTHA, R. 2004. An investigation into access control for mobile devices. Paper presented at the ISSA:1-10.

PITT, L.F., BERTHON, P.R. \& PLANGGER, K. 2012. The rise and rise of the Smartphone app: How is IT doing? Cutter Benchmark Review, 11(8):5-20.

PITT, L.F., PARENT, M., JUNGLAS, I., CHAN, A. \& SPYROPOULOU, S. 2011. Integrating the Smartphone into a sound environmental information systems strategy: principles, practices and a research agenda. Journal of Strategic Information Systems, 20(1):27-37.

RANSOM, D. 2009. Smartphone apps fuel business. The Wall Street Journal, 20 August.

RESEARCH2GUIDANCE. 2012. Whitepaper: the Smartphone app market 2013 [pdf]. Berlin. Available at: $\mathrm{http} / /$ www.research2guidance.com/shop/index.php/whitepaper-smartphone-app-market-2013 [accessed 2012-04-24].

SAS. 2012. JMP ${ }^{\circledR}$ Statistical discovery software: Comparing means: SAS Institute Inc. Available at: http://www.jmp.com/support/help/Compare_Means.shtml [accessed 2012-11-06].

SHEVCHIK, L. 2013. Mobile app industry to reach record revenue in 2013. Available at: http://blog.newrelic.com/2013/04/01/mobile-apps-industry-to-reach-record-revenue-in-2013/ [accessed 201211-06].

TENG, C.-C. \& HELPS, R. 2010. Mobile application development: Essential new directions for IT. Paper presented at the Information Technology: New Generations (ITNG) 2010 Seventh International Conference, 471-475. IEEE.

WANG, D., PARK, S. \& FESENMAIER, D.R. 2012. The role of smartphones in mediating the touristic experience. Journal of Travel Research, 51(4):371-387.

WATSON, R.T., PITT, L.F., BERTHON, P. \& ZINKHAN, G.M. 2002. U-commerce: extending the universe of marketing. Journal of the Academy of Marketing Science, 30(4):333-347.

WATSON, R.T., PITT, L.F., BERTHON, P. \& ZINKHAN, G.M. 2004. Marketing in the age of the network: From marketplace to U-space. Business Horizons, 4(6):33-40. 
WHITE, M. 2010. Information anywhere, any when: The role of the smartphone. Business Information Review, 27(4):242-247.

WOODCOCK, B., MIDDLETON, A. \& NORTCLIFFE, A. 2012. Considering the smartphone learner: an investigation into student interest in the use of personal technology to enhance their learning. Student Engagement and Experience Journal, 1(1):1-15.

YOUNG, J.R. 2011. Top smartphone apps to improve teaching, research, and your life. Education Digest, 76(9):12-15. 